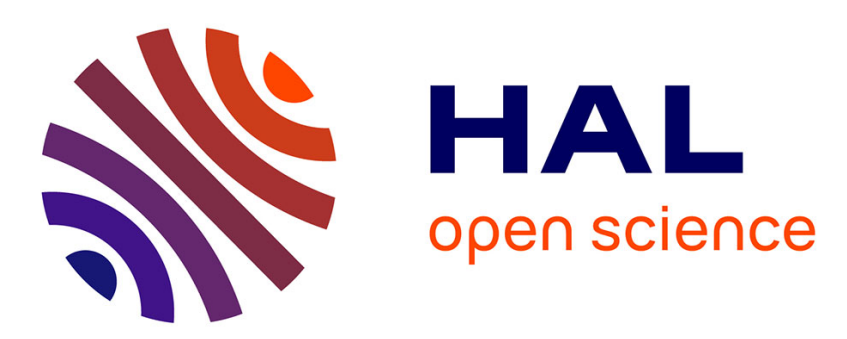

\title{
High resolution neutron diffraction study of $\alpha$-uranium
}

\author{
J. Fournier, A. Delapalme, C. Zeyen, G. Lander
}

\section{To cite this version:}

J. Fournier, A. Delapalme, C. Zeyen, G. Lander. High resolution neutron diffraction study of $\alpha$-uranium. Journal de Physique Colloques, 1979, 40 (C4), pp.C4-136-C4-137. 10.1051/jphyscol:1979443 . jpa-00218839

\section{HAL Id: jpa-00218839 https://hal.science/jpa-00218839}

Submitted on 1 Jan 1979

HAL is a multi-disciplinary open access archive for the deposit and dissemination of scientific research documents, whether they are published or not. The documents may come from teaching and research institutions in France or abroad, or from public or private research centers.
L'archive ouverte pluridisciplinaire HAL, est destinée au dépôt et à la diffusion de documents scientifiques de niveau recherche, publiés ou non, émanant des établissements d'enseignement et de recherche français ou étrangers, des laboratoires publics ou privés. 


\title{
High resolution neutron diffraction study of $\alpha$-uranium
}

\author{
J. M. Fournier, A. Delapalme, C. Zeyen (*) and G. H. Lander (**)
}

Centre d'Etudes Nucléaires de Grenoble, Département de Recherche Fondamentale, 85 X, 38041 Grenoble Cedex, France (*) Institut Laue-Langevin, BP 156, Centre de Tri, 38042 Grenoble Cedex, France

(**) Argonne National Laboratory, Argonne, Illinois 60439, U.S.A.

Résumé. - Des mesures précises de diffraction élastique de neutrons ont été menées à I.L.L. pour mettre en évidence le long des directions $(h 00),(0 k 0),(00 l)$ des distorsions périodiques du réseau associées à de possibles ondes de densité de charge (C.D.W.) au-dessous de $43 \mathrm{~K}$; le résultat est négatif. Nous avons mesuré pour la première fois les variations de paramètres cristallins liées à la transition du $1^{\text {ex }}$ ordre à $37 \mathrm{~K}$

$$
\left(\frac{\Delta a}{a}=-13 \times 10^{-5}( \pm 2) ; \frac{\Delta b}{b}=-4 \times 10^{-5}( \pm 2) ; \frac{\Delta c}{c}=6 \times 10^{-5}( \pm 2)\right) .
$$

Abstract. - We have performed at I.L.L. a high resolution neutron diffraction study of $\alpha-U$. The search along $(h 00),(0 k 0)$ and $(00 l)$ directions, for periodic lattice distortions associated with a possible charge-density wave (C.D.W.) below $43 \mathrm{~K}$ has been negative. We have measured for the first time the first order transition at $37 \mathrm{~K}$ and found :

$$
\left(\frac{\Delta a}{a}=-13 \times 10^{-5}( \pm 2) ; \frac{\Delta b}{b}=-4 \times 10^{-5}( \pm 2) ; \frac{\Delta c}{c}=6 \times 10^{-5}( \pm 2)\right)
$$

1. Introduction. - A number of unusual effects have been observed at $\approx 43 \mathrm{~K}$ in $\alpha$-uranium over the last 15 years [1]. Although most of the electronic properties (e.g. susceptibility) show only small effects compared with the anomalies in elastic constants and thermal expansion, the $43 \mathrm{~K}$ transition is assumed to be electronic in nature. Since the biggest effect occurs for elastic constants, low temperature phonon measurements [2] were carried out at O.R.N.L. and I.L.L. and show that the phonon intensities is reduced substantially at this temperature with smaller effects in the line width. The change in intensity presumably reflects a decrease in the vibrational amplitude, which may be related to changes in the interatomic forces below the transition.

Crystallographic investigations with both $\mathrm{X}$ rays [3] and neutrons [3, 4] failed to find any evidence for a true phase transition and lend further support to the idea of a subtle electronic transition. During the course of our phonon experiments at I.L.L., we also performed extensive elastic $q$ scan about (200) point, to search for a possible chargedensity wave.

In this paper, we report negative conclusion about this point and reinvestigations of results given by previous works $[3,4]$ with precise determination of the first order transitions at $37 \mathrm{~K}$.

2. Experimental and results. - The single crystal used was about $3 \times 8 \times 4.4 \mathrm{~mm}$ along the $a, b$ and $c$ directions. Experiments were done on D 10 at I.L.L., with a neutron wavelength, $\lambda=1.262 \AA$; the experimental $\lambda / 2$ contribution was about $4 \times 10^{-4}$. In scans along [h00], we had $13 \times 10^{6}$ counts (counting time $\simeq 5 \mathrm{~min}$.) on the $(200)$ reflection with a flat background, $150 \pm 40$. We could therefore detect very easily definite signals equal to the background, which means we had a $10^{-5}$ precision with respect the strongest reflections of this $\alpha$-uranium crystal (width of reflection : 12').

a) First we looked to find any peaks at low temperature around the (200) reflection. Profiles were performed at $30 \mathrm{~K}, 43 \mathrm{~K}$ and $60 \mathrm{~K}$, and we could not find any evidence for small peaks at $q_{x}=0.11$ r.l.u. ; the profiles were the same inside an error bar of $5 \times 10^{-6}$ times the strongest reflections.

b) A precise check of the parameter-temperature dependence was carried out between $26 \mathrm{~K}$ and $65 \mathrm{~K}$. We see easily the $43 \mathrm{~K}$ second order transition and clearly (Fig. 1) the $37 \mathrm{~K}$ first order transition on the $\Delta \theta_{a}$ jump. This change in the (400), (080) and (006) position at the transition temperature gives the relative change in the crystallographic parameters :

$$
\begin{aligned}
\frac{\Delta a}{a}=-13 \times 10^{-5}( \pm 2) ; & \frac{\Delta b}{b}=-4 \times 10^{-5}( \pm 2) \\
& \text { and } \frac{\Delta c}{c}=6 \times 10^{-5}( \pm 2) .
\end{aligned}
$$




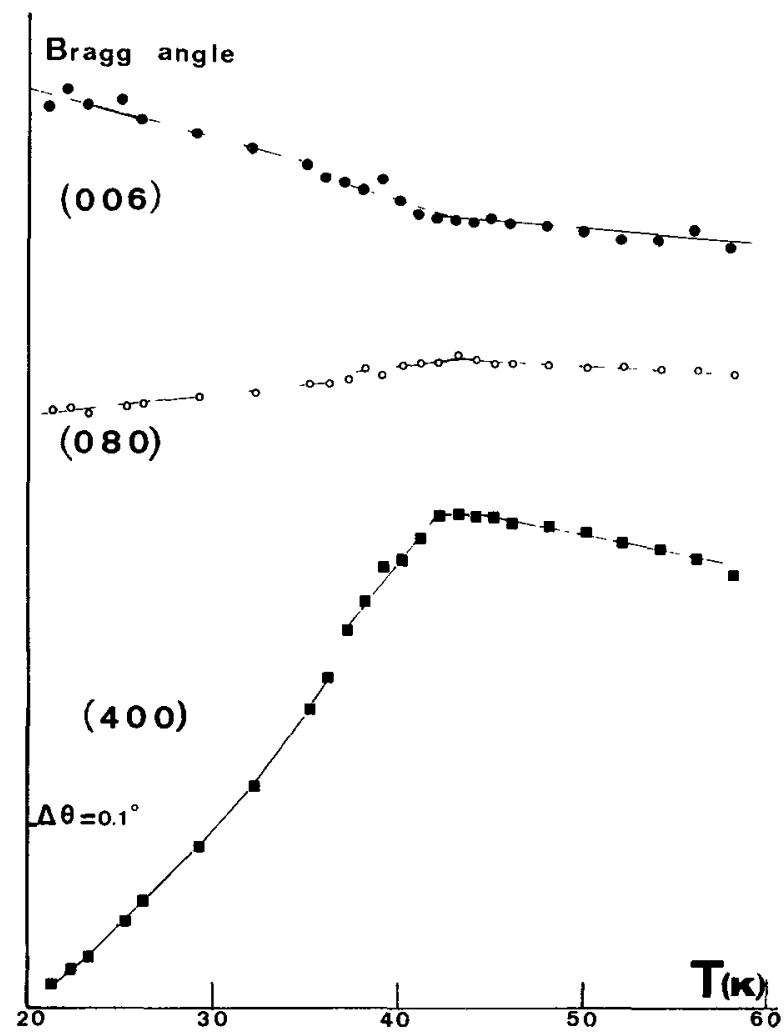

Fig. 1. - Bragg angle-temperature dependence for $(400)$, (080) and (006) reflections.

Figure 2 shows the evolution of integrated intensities in this temperature interval and confirms previous results on peak intensities [4], where the change in intensity is more pronounced for the (400) and (006) reflections than for the $(080)$ one.

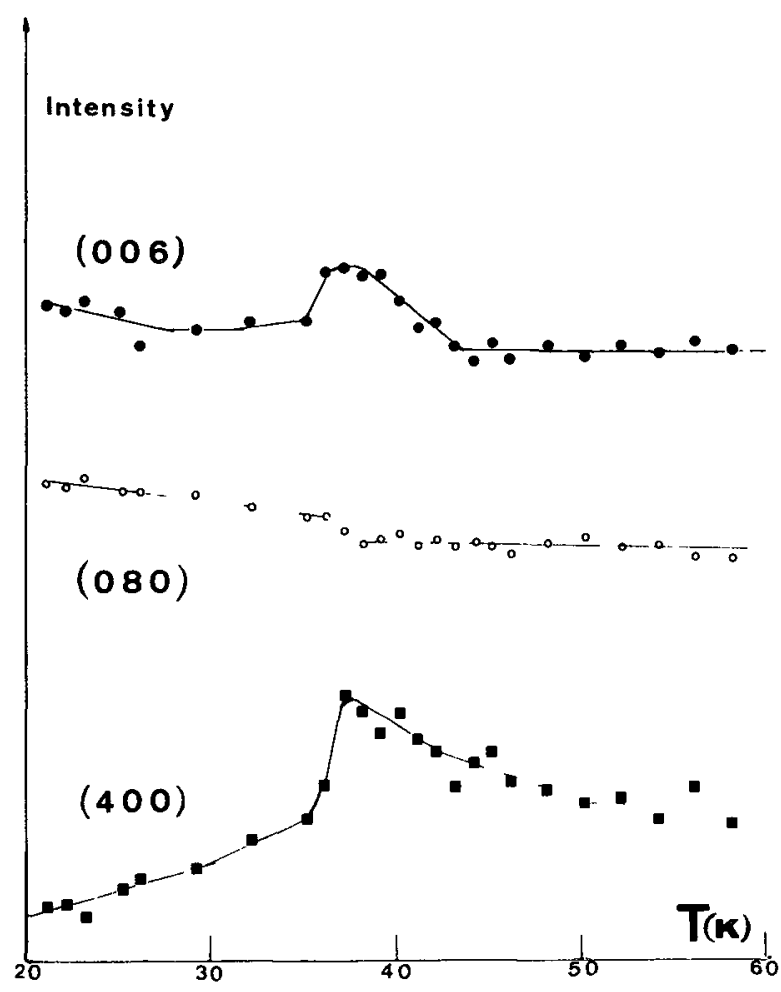

Fig. 2. - Integrated intensities versus temperature for (400), $(080)$ and (006) reflections.

It is seen from the examination of figures 1 and 2 that the change in integrated intensity - probably related to extinction phenomena - is more connected with the first order transition at $37 \mathrm{~K}$ than with the second order transition at $43 \mathrm{~K}$.

\section{References}

[1] Smrrh, T. F., Fisher, E. S., J. Low Temp. Phys. 12 (1973) 631.

[2] Fournier, J. M., Delapalme, A., Lander, G. H., Pynn, R. WAKabashi, A. N., NiCKLOW, R. M., D. C. Meeting of the American Physical Society (1978).

[3] Barrett, C. S., Mueller, M. H., Hitterman, R. L., Phys. Rev. 129 (1963) 625.

[4] Lander, G. H., Mueller, M. H., Acta. Crystallogr. B 26 (1970) 129. 